\title{
FINITE ELEMENT BOND MODELS FOR SEVEN-WIRE PRESTRESSING STRANDS IN CONCRETE CROSSTIES
}

\author{
Hailing Yu and David Jeong \\ Structures and Dynamics Division \\ John A. Volpe National Transportation Systems Center \\ U.S. Department of Transportation \\ Cambridge, MA 02142, U.S.A.
}

\begin{abstract}
Seven-wire strands are commonly used in pretensioned concrete ties, but its bonding mechanism with concrete needs further examination to provide a better understanding of some concrete tie failure modes. As a key component in the finite element (FE) analysis of concrete crossties, macro-scale or phenomenological FE bond models are developed for sevenwire strands in this paper. The strand-concrete interfaces are homogenized with a thin layer of cohesive elements applied between the strand and concrete elements. Further, the cohesive elements are assigned traction-displacement constitutive or bond relations that are defined in terms of normal and shear stresses versus interfacial dilation and slip. The bond relations are developed within an elasto-plastic framework that characterizes the adhesive, frictional and/or dilatational bonding mechanisms in the interface. The yield functions and plastic flow rules specific for the seven-wire strands are presented. The bond parameters are calibrated from untensioned pullout tests and pretensioned prism tests conducted on concrete specimens. The bond models are then verified with (1) the surface strain data measured on actual concrete crossties made at a tie manufacturing plant, and (2) the force-displacement relation obtained in a center negative moment test conducted also on concrete crossties.
\end{abstract}

\section{INTRODUCTION}

Concrete ties are made by embedding prestressing steel reinforcements in concrete. The interaction between steel reinforcements and concrete, commonly referred to as bond, affects several important aspects of concrete crosstie performance, including the transfer length needed to transfer the prestress forces from the reinforcements to the concrete, the bursting/splitting propensity of concrete due to pretension release in the reinforcements, and the ultimate flexural moment capacity prior to failure. Bond modeling is a key component in the finite element (FE) analysis of concrete crossties. One objective of Volpe Center's ties and fasteners research, sponsored by the Federal Railroad Administration, is to develop realistic concrete tie models, including FE bond models for various reinforcement interfaces, and apply the models in predicting and evaluating the concrete tie performance.

Concrete ties are a promising alternative to wood ties used in railroad tracks. However, concrete ties have displayed multiple failure modes in the field, such as chemical degradation, prestress cracks, flexural cracks, rail seat deterioration, freeze-thaw cracks and shoulder/fastener wear or fatigue, and these failures have led to premature replacement of track components and sometimes derailment accidents [1]. Two of these failure modes are illustrated in Figures 1 and 2. Figure 1 shows a widespread horizontal cracking pattern observed in concrete ties installed during the 1994-98 period on the Northeast Corridor [2]. Figure 2 shows multiple center negative cracks observed on concrete ties retrieved from the site of the July 18, 2013, CSX freight train derailment accident in Bronx, New York [3-4]. While these failures can occur in concrete ties with other types of reinforcements, the concrete ties in these two particular cases have seven-wire strands as reinforcements. This indicates a need to further examine the bond behavior of the seven-wire strands.

This paper develops macro-scale or phenomenological bond models for seven-wire strands commonly used in pretensioned concrete ties. The basic bond mechanisms of these strands include adhesion and friction. In addition, the natural spiral surfaces of the strands interlock with the 
matching inner surfaces of the concrete. When the strand and concrete surfaces slip relative to each other as the pretension in the strands is released, normal dilation (or dilatation) occurs on the strand-concrete interfaces as a result of (1) Hoyer effect, and (2) mismatched steel and concrete surfaces. The interfacial dilation provides additional bonding between the steel strands and the concrete.

This paper first describes the elasto-plastic bond modeling approach adopted in this study. The governing equations, solution approaches and yield functions/plastic flow rules specific for the bond of seven-wire strands are presented. The calibration of the bond parameters is then carried out based on untensioned pullout tests and pretensioned prism tests conducted on concrete specimens at the Kansas State University (KSU). The bond models developed in this study are then verified with the surface strain data measured on actual concrete crossties made at a tie manufacturing plant as well as the force-displacement relation obtained in a center negative moment test.

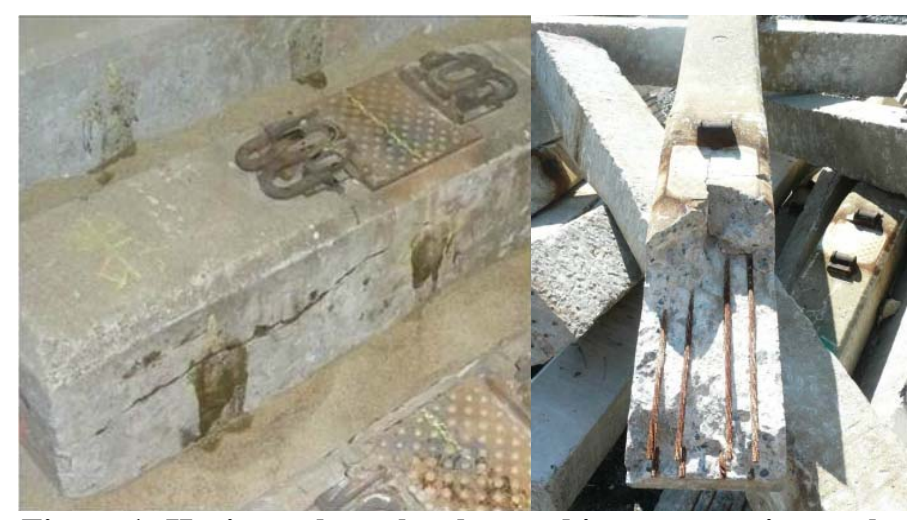

Figure 1: Horizontal cracks observed in concrete ties on the Northeast Corridor [2].

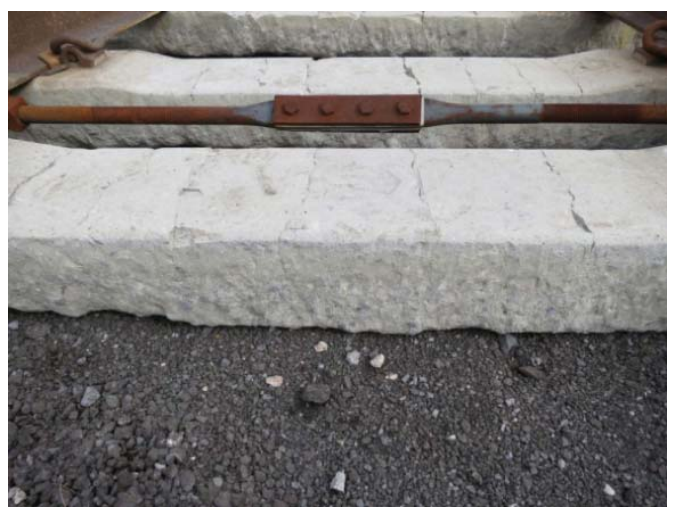

Figure 2: Center negative cracks on concrete ties retrieved from the site of the July 18, 2013, CSX freight train derailment accident in Bronx, New York.

\section{ELASTOPLASTIC BOND MODELING APPROACH}

The commercial FE analysis software Abaqus is employed in this study [5]. The concrete material is modeled with concrete damaged plasticity, and the modeling framework and model parameter calibration are described in detail in previous publications [6-7]. The elasto-plastic bond model development in this paper follows the general plasticity theory and FE procedure described by Zienkiewicz and Taylor [8]. User subroutines were written for both axisymmetric and 3D cohesive elements in Abaqus, but only the 3D governing equations, similar to the theoretical basis for frictional contact developed by Michalowski and Mroz [9], are presented here. The same modeling framework was previously employed in the development of a bond model for smooth wires [10].

\section{Governing Equations}

Figure 3 shows the local coordinate system defined for a 3D cohesive element [5]. It includes a normal (or thickness) direction and two shear directions, depicted by unit vectors $\mathbf{n}, \mathbf{s}$ and $\mathbf{t}$, respectively. The traction-displacement constitutive relation type is adopted. The interface stress tensor $\sigma$ includes a normal component $\sigma$ and two shear components $\tau_{1}$ and $\tau_{2}$,

$\boldsymbol{\sigma}=\sigma \mathbf{n}+\tau_{1} \mathbf{s}+\tau_{2} \mathbf{t}$

The magnitude of the total shear stress is

$|\tau|=\sqrt{\tau_{1}^{2}+\tau_{2}^{2}}$

The interface displacement tensor $\mathbf{u}$ includes dilation $u_{\mathrm{n}}$ and slips $u_{\mathrm{t} 1}$ and $u_{\mathrm{t} 2}$

$\mathbf{u}=u_{\mathrm{n}} \mathbf{n}+u_{\mathrm{t} 1} \mathbf{s}+u_{\mathrm{t} 2} \mathbf{t}$

which can be decomposed into elastic and plastic components

$\mathbf{u}=\mathbf{u}^{\mathrm{el}}+\mathbf{u}^{\mathrm{pl}}$

The magnitude of the total plastic slip is written as

$$
\left|u_{\mathrm{t}}^{\mathrm{p}}\right|=\sqrt{\left(u_{\mathrm{t} 1}^{\mathrm{pl}}\right)^{2}+\left(u_{\mathrm{t} 2}^{\mathrm{pl}}\right)^{2}}
$$

Elasticity of the interface material indicates

$\boldsymbol{\sigma}=\mathbf{D}^{\mathrm{e}} \mathbf{u}^{\mathrm{el}}=\mathbf{D}^{\mathrm{e}}\left(\mathbf{u}-\mathbf{u}^{\mathrm{pl}}\right)$

where $\mathbf{D}^{\mathrm{e}}$ is the elastic matrix with the unit force/length ${ }^{3}$. Assuming decoupled elastic normal-shear behavior, we have $\mathbf{D}^{\mathrm{e}}$ in the following matrix form 


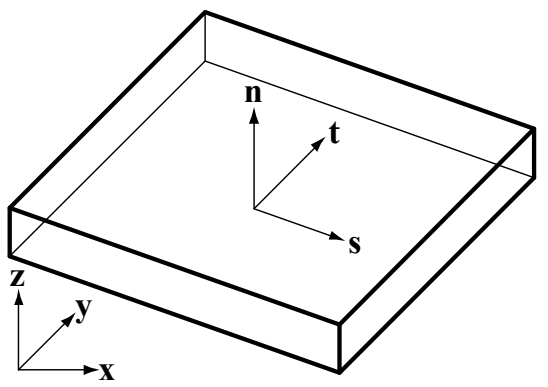

Figure 3: Local coordinate system $(n, s, t)$ for a 3D cohesive element [5].

$\mathbf{D}^{\mathrm{e}}=\left[\begin{array}{ccc}D_{\mathrm{nn}}^{\mathrm{e}} & 0 & 0 \\ 0 & D_{\mathrm{ns}}^{\mathrm{e}} & 0 \\ 0 & 0 & D_{\mathrm{nt}}^{\mathrm{e}}\end{array}\right]$

where the normal $\left(D_{\mathrm{nn}}^{\mathrm{e}}\right)$ and shear elastic stiffness $\left(D_{\mathrm{ns}}^{\mathrm{e}}, D_{\mathrm{nt}}^{\mathrm{e}}\right)$ are the only non-trivial components. Isotropy in the shear plane would further imply $D_{\mathrm{ns}}^{\mathrm{e}}=D_{\mathrm{nt}}^{\mathrm{e}}$.

For elastic loading and unloading, the yield function $F$ satisfies $F<0$. When plastic loading occurs, the stress stays on the yield surface:

$F=0$

The plastic flow rate can be calculated from the plastic potential $Q$ as follows

$\mathrm{d} \mathbf{u}^{\mathrm{pl}}=\mathrm{d} \lambda \frac{\partial Q}{\partial \boldsymbol{\sigma}}$

where $\mathrm{d} \mathbf{u}^{\mathrm{pl}}$ is the rate of the plastic interface displacement, and $\mathrm{d} \lambda$ is a proportionality constant. Eq. (9) implies an associated flow rule when $Q=F$ and a non-associated flow rule when $Q \neq F$.

This paper develops two elasto-plastic bond models, one considers friction only, and the other considers adhesive, frictional and dilatational mechanisms. Table 1 defines yield functions, plastic potentials, adhesion, and plastic flow rules for the two models and summarizes the constants or parameters needed to completely define the material models.

Here a form of the adhesive strength $a$ depending linearly on the total plastic slip $\left|u_{\mathrm{t}}^{\mathrm{p}}\right|$ is chosen, with $a_{0}$ being the initial adhesive strength and $u_{\mathrm{tc}}^{\mathrm{pl}}$ the plastic slip amount at which adhesion is first broken completely. Figure 4 shows the plot of $a$ as a function of $u_{\mathrm{t}}^{\mathrm{pl}}$.

The frictional mechanism is characterized with the friction angle $\phi$, or the coefficient of friction $\tan \phi$. The dilatational effect is accounted for by a dilatational factor $\tan \psi$, which measures the interface's plastic dilation rate as a proportion of the plastic slip rate, $\mathrm{d} u_{\mathrm{n}}^{\mathrm{pl}}=\tan \psi\left|\mathrm{d} u_{\mathrm{t}}^{\mathrm{pl}}\right|$

Figure 5 shows the yield surfaces and the plastic flow rule. The plastic flow vectors for a non-dilatational interface are assumed to be parallel to the $\tau$-axis, whereas the plastic flow vectors for a dilatational interface are assumed to form a dilatational angle $\psi$ with the $\tau$-axis.

\section{Local Iteration}

At the element level, updated stress $\sigma$ is sought with given initial stress $\sigma_{0}$, initial displacement $\mathbf{u}_{0}$ and incremental displacement du. This can be achieved by solving the following equation involving the residual function $\mathbf{R}$,

$\mathbf{R}=\mathbf{0}$

Table 1. Definition of elasto-plastic bond models for sevenwire strands.

\begin{tabular}{|c|c|c|}
\hline & Frictional model & $\begin{array}{c}\text { Adhesive, frictional and } \\
\text { dilatational model }\end{array}$ \\
\hline $\begin{array}{l}\text { Yield } \\
\text { function }\end{array}$ & $F=|\tau|+\sigma \tan \phi$ & $F=|\tau|+\sigma \tan \phi-a$ \\
\hline $\begin{array}{l}\text { Plastic } \\
\text { potential }\end{array}$ & $Q=|\tau|$ & $Q=|\tau|+\sigma \tan \psi$ \\
\hline Adhesion & & $a=\left\{\begin{array}{cc}a_{0}\left(1-\frac{\left|u_{\mathrm{t}}^{\mathrm{p}}\right|}{u_{\mathrm{tc}}^{\mathrm{pl}}}\right), & \text { if }\left|u_{\mathrm{t}}^{\mathrm{pl}}\right| \leq u_{\mathrm{tc}}^{\mathrm{p}} \\
0, & \text { if }\left|u_{\mathrm{t}}^{\mathrm{p} \mid}\right|>u_{\mathrm{tc}}^{\mathrm{p}}\end{array}\right.$ \\
\hline $\begin{array}{l}\text { Plastic } \\
\text { flow rule }\end{array}$ & $\begin{array}{c}\mathrm{d} u_{\mathrm{n}}^{\mathrm{pl}}=0 \\
\tau_{2} \mathrm{~d} u_{\mathrm{t} 1}^{\mathrm{pl}}=\tau_{1} \mathrm{~d} u_{\mathrm{t} 2}^{\mathrm{pl}}\end{array}$ & $\begin{array}{l}|\tau| \tan \psi \mathrm{d} u_{\mathrm{t} 1}^{\mathrm{pl}}=\tau_{1} \mathrm{~d} u_{\mathrm{n}}^{\mathrm{pl}} \\
|\tau| \tan \psi \mathrm{d} u_{\mathrm{t} 2}^{\mathrm{pl}}=\tau_{2} \mathrm{~d} u_{\mathrm{n}}^{\mathrm{pl}}\end{array}$ \\
\hline $\begin{array}{l}\text { Material } \\
\text { constants }\end{array}$ & $\begin{array}{c}D_{\mathrm{nn}}^{\mathrm{e}} \\
D_{\mathrm{ns}}^{\mathrm{e}}\left(=D_{\mathrm{nt}}^{\mathrm{e}}\right) \\
\tan \phi\end{array}$ & $\begin{array}{c}D_{\mathrm{nn}}^{\mathrm{e}} \\
D_{\mathrm{ns}}^{\mathrm{e}}\left(=D_{\mathrm{nt}}^{\mathrm{e}}\right) \\
\tan \phi \\
a_{0} \\
u_{\mathrm{tc}}^{\mathrm{pl}} \\
\tan \psi\end{array}$ \\
\hline
\end{tabular}

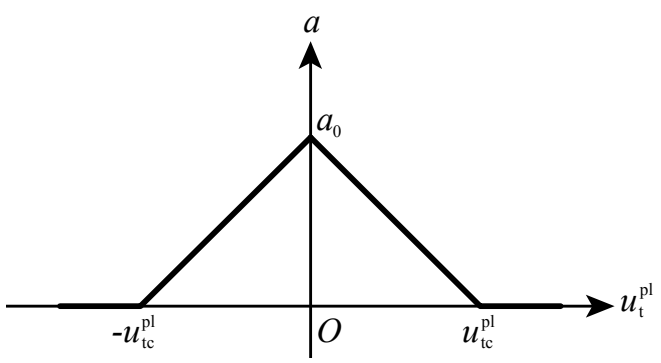

Figure 4: Adhesive strength as a function of plastic slip. 


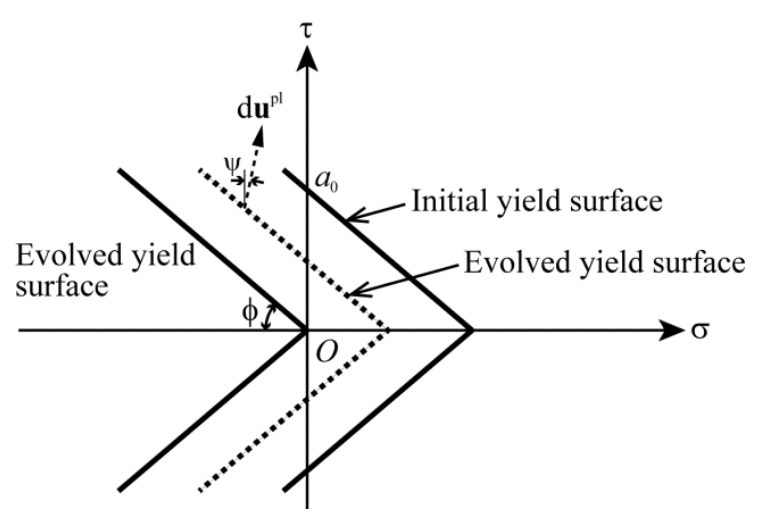

Figure 5: Yield surfaces and plastic flow rule.

which can be defined according to the plastic loading condition Eq. (8) and the plastic flow rules. For the frictional model, the residual function is defined as

$\mathbf{R}=\left\{\begin{array}{c}F \\ -\mathrm{d} u_{\mathrm{n}}^{\mathrm{pl}} \\ \tau_{2} \mathrm{~d} u_{\mathrm{t} 1}^{\mathrm{pl}}-\tau_{1} \mathrm{~d} u_{\mathrm{t} 2}^{\mathrm{pl}}\end{array}\right\}$

For the adhesive, frictional and dilatational model, the residual function is defined as

$\mathbf{R}=\left\{\begin{array}{c}F \\ |\tau| \tan \psi \mathrm{d} u_{\mathrm{t} 1}^{\mathrm{pl}}-\tau_{1} \mathrm{~d} u_{\mathrm{n}}^{\mathrm{pl}} \\ |\tau| \tan \psi \mathrm{d} u_{\mathrm{t} 2}^{\mathrm{p}}-\tau_{2} \mathrm{~d} u_{\mathrm{n}}^{\mathrm{pl}}\end{array}\right\}$

The plastic displacement rate du ${ }^{\mathrm{pl}}$ in Eqs. (12-13) can be calculated from the rate form of the elasticity equation Eq. (6)

$\mathrm{d} \mathbf{u}^{\mathrm{pl}}=\mathrm{d} \mathbf{u}-\mathbf{C}^{\mathrm{e}} \mathrm{d} \boldsymbol{\sigma}$

where $\mathbf{C}^{\mathrm{e}}$ is the elastic compliance matrix

$\mathbf{C}^{\mathrm{e}}=\mathbf{D}^{\mathrm{e}^{-1}}$

Eq. (11) is solved by applying the Newton-Raphson method and performing the following substitutive iterations at the element material level until convergence is achieved,

$\boldsymbol{\sigma}_{i+1}=\boldsymbol{\sigma}_{i}-\left(\frac{\partial \mathbf{R}}{\partial \boldsymbol{\sigma}}\right)_{i}^{-1} \mathbf{R}_{i}$

where the subscripts " $i$ " and " $i+1$ " indicate the iteration sequence numbers. Convergence is considered to be achieved when the norm of the vector $\mathbf{R}$ is sufficiently small.

\section{Global Stiffness Matrix}

In incremental FE analyses, the user material's Jacobian matrix $\mathbf{D}^{\mathrm{ep}}$ is sought to determine the stress increment $\mathrm{d} \sigma$ in terms of the displacement increment du,

$\mathrm{d} \boldsymbol{\sigma}=\mathbf{D}^{\mathrm{ep}} \mathrm{du}$

This element stiffness matrix is passed on to assemble the stiffness matrix used in the global iterations and therefore also referred to as the global stiffness matrix of the element.

By enforcing the consistency condition for plastic loading

$\mathrm{d} F=\left(\frac{\partial F}{\partial \boldsymbol{\sigma}}\right)^{\mathrm{T}} \mathrm{d} \boldsymbol{\sigma}+\frac{\partial F}{\partial a} \mathrm{~d} a=0$

$\mathbf{D}^{\mathrm{ep}}$ can be obtained as follows with nonzero adhesive strength

$\mathbf{D}^{\mathrm{ep}}=\mathbf{D}^{\mathrm{e}}-\frac{\mathbf{D}^{\mathrm{e}} \frac{\partial Q}{\partial \boldsymbol{\sigma}}\left(\frac{\partial F}{\partial \boldsymbol{\sigma}}\right)^{\mathrm{T}} \mathbf{D}^{\mathrm{e}}}{\left(\frac{\partial F}{\partial \boldsymbol{\sigma}}\right)^{\mathrm{T}} \mathbf{D}^{\mathrm{e}} \frac{\partial Q}{\partial \boldsymbol{\sigma}}-\frac{\partial F}{\partial a}\left(\frac{\partial a}{\partial \mathbf{u}^{\mathrm{pl}}}\right)^{\mathrm{T}} \frac{\partial Q}{\partial \boldsymbol{\sigma}}}$

When the adhesive strength has reached zero, Eq. (19) is simplified as

$$
\mathbf{D}^{\mathrm{ep}}=\mathbf{D}^{\mathrm{e}}-\frac{\mathbf{D}^{\mathrm{e}} \frac{\partial Q}{\partial \boldsymbol{\sigma}}\left(\frac{\partial F}{\partial \boldsymbol{\sigma}}\right)^{\mathrm{T}} \mathbf{D}^{\mathrm{e}}}{\left(\frac{\partial F}{\partial \boldsymbol{\sigma}}\right)^{\mathrm{T}} \mathbf{D}^{\mathrm{e}} \frac{\partial Q}{\partial \boldsymbol{\sigma}}}
$$

\section{CALIBRATION OF BOND MODEL PARAMETERS}

KSU conducted untensioned pullout tests and pretensioned concrete prism tests to evaluate the bonding quality of different reinforcements including both wires and strands [11-12]. We have employed the data involving the seven-wire strands from these tests to calibrate our bond model parameters listed in Table 1.

Figure 6 shows the setup of the untensioned pullout test that we simulated. A seven-wire steel strand with a nominal diameter of $3 / 8$ in. $(9.525 \mathrm{~mm})$ is embedded in a concrete matrix with a 4 in. $(101.6 \mathrm{~mm})$ embedment length and a 4 in. $(101.6 \mathrm{~mm})$ bond breaking length. The steel tube encasing the concrete specimen has an inner diameter of 4 in. $(101.6 \mathrm{~mm})$. The pullout force and the displacements at the unloaded and loaded ends of the steel strand were recorded. Axisymmetric models were developed to simulate the pullout tests.

Figure 7 shows the cross section of the concrete prism used in the pretensioned concrete prism test. There are four seven-wire strands embedded in the concrete matrix. The prism measures 5.5 in. $(139.7 \mathrm{~mm})$ on each side of its cross section and 69 in. $(1.75 \mathrm{~m})$ in length, and every two strands are spaced 2 in. $(50.8 \mathrm{~mm})$ apart. The strands in the concrete prisms were 
pretensioned to 17,415 pound force $(77,466 \mathrm{~N})$, equivalent to a nominal initial tensile stress of $157,678 \mathrm{psi}(1,087.2 \mathrm{MPa})$. Once the concrete reached a desired compressive strength, the pretension was released with the strands cut at the prism ends. There were three concrete release strengths: $3,500,4,500$ and $6,000 \mathrm{psi}(24.1,31.0$ and 41.4 MPa). Concrete surface strains were then measured for each prism and used to calculate the transfer length. In modeling, quarter symmetry in the cross section and half symmetry over the length were assumed, resulting in one-eighth of the prism being modeled.

The bond parameters are determined and shown in Table 2 for the frictional and the adhesive/frictional/dilatational bond models. For the frictional model, a high normal elastic stiffness $D_{\mathrm{nn}}^{\mathrm{e}}$ was chosen to ensure no penetration of the interface, a moderate shear elastic stiffness was chosen to ensure good convergence, and a coefficient of friction $(\tan \phi)$ of 0.45 was adopted based on the average coefficient of friction measured between machined mild steel and concrete for normal stresses between 1 and 68,000 psi (6.9 $\mathrm{kPa}$ and $468.8 \mathrm{MPa})$ [13].

For the adhesive, frictional and dilatational model, the normal and shear elastic stiffness parameters were assumed to be the same as those in the frictional model. The remaining parameters were calibrated from the KSU pullout and prism tests. Table 3 shows the concrete and steel material parameters used in the simulations of these tests. In the bond parameter calibration, only the data corresponding to the concrete release strength of $6,000 \mathrm{psi}(41.4 \mathrm{MPa})$ was considered in the simulations of the prism tests.

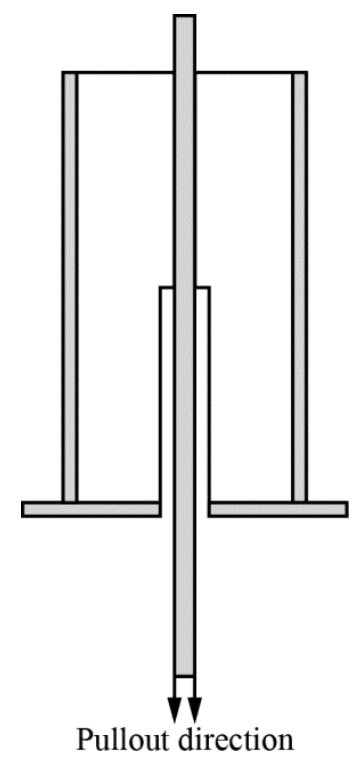

Figure 6: Illustration of the un-tensioned pullout test conducted on a concrete specimen embedded with a sevenwire strand.

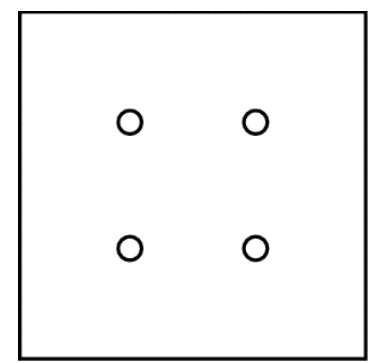

Figure 7: Illustration of the cross section of a pretensioned concrete prism with seven-wire strands.

Table 2. Calibrated bond model parameters.

\begin{tabular}{lcc}
\hline & Frictional model & $\begin{array}{c}\text { Adhesive, frictional } \\
\text { and dilatational } \\
\text { model }\end{array}$ \\
\hline$D_{\mathrm{nn}}^{\mathrm{e}}$ & $92,630,000 \mathrm{lbf} / \mathrm{in}^{3}$ & $92,630,000 \mathrm{lbf} / \mathrm{in}^{3}$ \\
$\left(25,144.1 \mathrm{~N} / \mathrm{mm}^{3}\right)$ & $\left(25,144.1 \mathrm{~N} / \mathrm{mm}^{3}\right)$ \\
\hline$D_{\mathrm{ns}}^{\mathrm{e}}\left(=D_{\mathrm{nt}}^{\mathrm{e}}\right)$ & $385,958 \mathrm{lbf} / \mathrm{in}^{3}$ & $385,958 \mathrm{lbf} / \mathrm{in}^{3}$ \\
$\left(104.8 \mathrm{~N} / \mathrm{mm}^{3}\right)$ & $\left(104.8 \mathrm{~N} / \mathrm{mm}^{3}\right)$ \\
\hline $\tan \phi$ & 0.45 & 0.3 \\
\hline$a_{0}$ & & $600 \mathrm{psi}$ \\
& & $(4.14 \mathrm{MPa})$ \\
\hline$u_{\mathrm{tc}}^{\mathrm{pl}}($ in $)$ & $0.08 \mathrm{in}$. \\
\hline $\tan \psi$ & $(2.03 \mathrm{~mm})$ \\
\hline
\end{tabular}

Table 3. Concrete and steel material parameters used in simulations for bond parameter calibration.

\begin{tabular}{|c|c|c|c|}
\hline \multicolumn{2}{|l|}{ Concrete } & \multirow{2}{*}{\multicolumn{2}{|c|}{ Steel }} \\
\hline Nominal strength $f_{\mathrm{c}}$ & $\begin{array}{r}6,000 \mathrm{psi} \\
(41.4 \mathrm{MPa})\end{array}$ & & \\
\hline Young's modulus $E$ & $\begin{array}{r}4,028 \mathrm{ksi} \\
(27.8 \mathrm{GPa})\end{array}$ & $\begin{array}{l}\text { Young's } \\
\text { modulus }\end{array}$ & $\begin{array}{r}30,000 \mathrm{ksi} \\
(206.8 \mathrm{GPa})\end{array}$ \\
\hline Tensile strength $\sigma_{\mathrm{t} 0}$ & $\begin{array}{r}478.8 \mathrm{psi} \\
(3.3 \mathrm{MPa}) \\
\end{array}$ & $\begin{array}{c}\text { Yield } \\
\text { strength }\end{array}$ & $\begin{array}{r}270,600 \mathrm{psi} \\
(1,865.7 \mathrm{MPa}) \\
\end{array}$ \\
\hline $\begin{array}{l}\text { Compressive } \\
\text { strength } \sigma_{\mathrm{cu}}\end{array}$ & $\begin{array}{r}5977.8 \mathrm{psi} \\
(41.2 \mathrm{MPa}) \\
\end{array}$ & & \\
\hline
\end{tabular}

Figure 8 shows the pullout force-unloaded end displacement plots for test versus FE results. The test data were averaged over the data of six specimens.

Figure 9 compares the concrete surface strain profile predicted by FE modeling versus measurements made in the prism tests. The average of six test measurements is shown in Figure 9. The test measurements are consistently higher than the unadjusted FE predictions. It was reported that for logistic reasons, concrete strains could not be measured at the same time the strand pretension was released, and the time lapse between the two events led to considerable concrete creep by the time of the strain measurement. A method to account for the added strains due to creep was therefore needed so that meaningful comparisons can be made between the test data and the simulation results. 


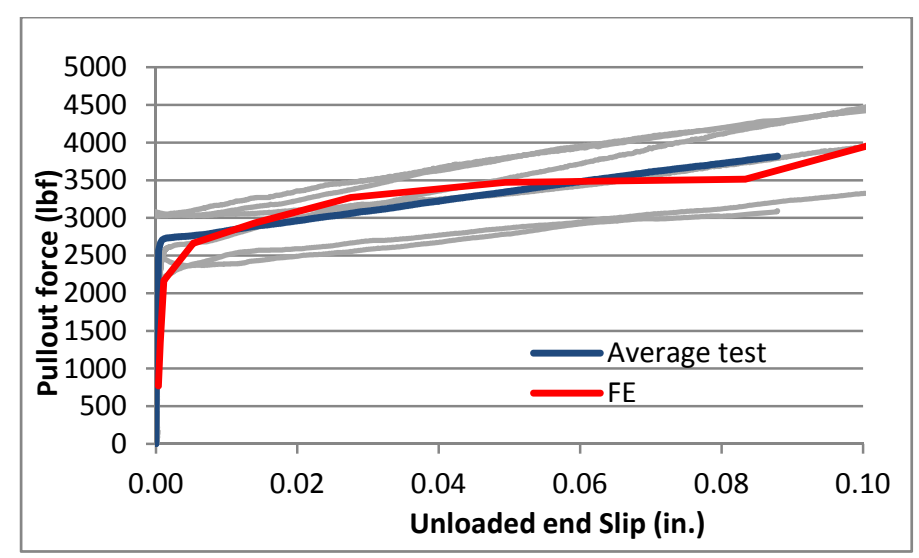

Figure 8: Pullout force-unloaded end displacement curves: test versus $\mathrm{FE}$ results $(1 \mathrm{lbf}=4.448 \mathrm{~N}, 1 \mathrm{in} .=25.4 \mathrm{~mm})$.

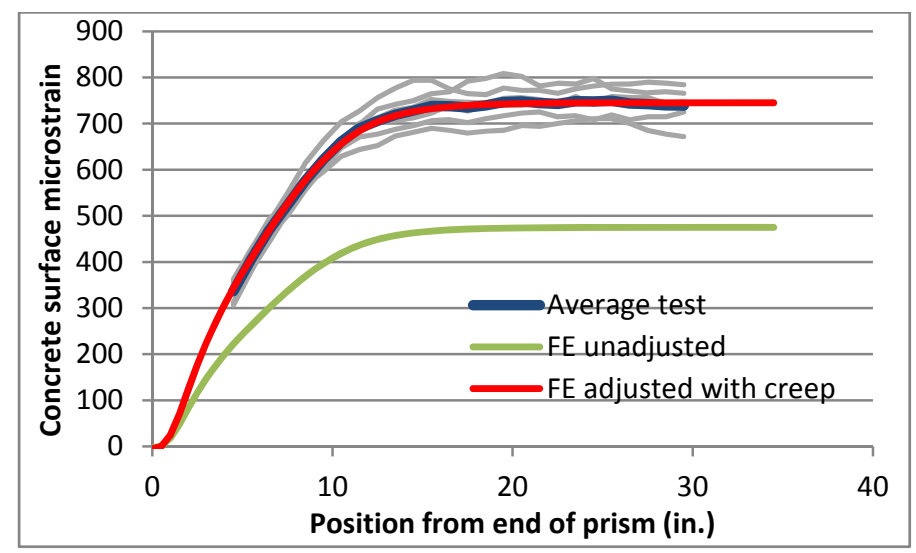

Figure 9: Measured versus FE predicted surface strain profile in the concrete prism $(1$ in. $=25.4 \mathrm{~mm})$.

Bazant and Baweja postulated that for a constant uniaxial stress $\sigma$ within the service range and applied at age $t^{\prime}$, the strain $\varepsilon$ at age $t$ can be written as [14]

$\varepsilon(t)=J\left(t, t^{\prime}\right) \sigma+\varepsilon_{\mathrm{sh}}(t)+\alpha \Delta T(t)$

where $J$ is the compliance function, $\varepsilon_{\mathrm{sh}}$ the shrinkage strain, $\alpha$ the thermal expansion coefficient, and $\Delta T$ the temperature change. The compliance function can be further expressed in elastic and creep terms as

$J\left(t, t^{\prime}\right)=1 / E\left(t^{\prime}\right)+C_{0}\left(t, t^{\prime}\right)+C_{\mathrm{d}}\left(t, t^{\prime}, t_{0}\right)$

where $E\left(t^{\prime}\right)$ is the modulus of elasticity at loading age $t^{\prime}$, $C_{0}\left(t, t^{\prime}\right)$ is the basic creep compliance, and $C_{\mathrm{d}}\left(t, t^{\prime}, t_{0}\right)$ is the creep compliance due to simultaneous drying. Assuming only the basic creep mechanism is in effect, we rewrite Eq. (21) as

$$
\varepsilon(t)=\sigma / E\left(t^{\prime}\right)+\sigma C_{0}\left(t, t^{\prime}\right)
$$

If we further assume that at age $t^{\prime}$
$\sigma=E\left(t^{\prime}\right) \varepsilon\left(t^{\prime}\right)$

then we can obtain an estimate of $C_{0}\left(t, t^{\prime}\right)$ as follows,

$C_{0}\left(t, t^{\prime}\right)=\frac{\varepsilon(t)-\varepsilon\left(t^{\prime}\right)}{E\left(t^{\prime}\right) \varepsilon\left(t^{\prime}\right)}$

In our analyses, we substituted $\varepsilon(t)$ for the average maximum test measurement and $\varepsilon\left(t^{\prime}\right)$ for the average maximum FE prediction to obtain an estimation of $C_{0}$. Figure 9 shows both the original FE predicted strains and the same strains adjusted with creep strains based on an estimated $C_{0}=0.14$ microstrain/psi (20.3 microstrain/MPa).

\section{VERIFICATION WITH TEST DATA}

The FE bond models developed in this paper were verified with two sets of test data on concrete ties made with seven-wire strands, (1) concrete surface strain data obtained on actual pretension released concrete crossties made in a plant, and (2) force-displacement relation obtained from a center negative moment test.

\section{Surface Strain Measurement on Concrete Crossties}

Concrete crossties were made at a plant with over a dozen prestressing wires or strands [15]. Both Whittemore gauge and Laser Speckle Imaging (LSI) methods were applied to obtain strain data on the concrete surfaces. FE simulations of the pretension release in the seven-wire strands were conducted. Again the measured concrete surface strains had significant creep components, and the creep compliance parameters $C_{0}$ were estimated according to Eq. (25) to be 0.17 and 0.096 microstrain/psi (24.7 and 13.9 microstrain/MPa) for Whittemore gauge and LSI measured data, respectively. Then an inverse operation to Eq. (23) was conducted to remove the creep strains from the test data,

$\varepsilon\left(t^{\prime}\right)=\frac{\varepsilon(t)}{1+E\left(t^{\prime}\right) C_{0}\left(t, t^{\prime}\right)}$

The adjusted test data are then compared in Figure 10 with the FE predicted strains using the adhesive, frictional and dilatational bond model. This allows all three sets of results to be compared directly. The averages of the multiple measurement data obtained under each measuring method are shown in Figure 10. The FE analysis used the concrete and steel material properties in Table 3 and the calibrated bond model parameters in Table 2. The FE results appear to fall within the scattering of the experimental data obtained from the two strain measuring methods. It is further noted that the average concrete release strength of the concrete ties made with the seven-wire strands in the plant was 5,277 psi (36.4 MPa), lower than the $6,000 \mathrm{psi}(41.4 \mathrm{MPa})$ concrete release strength employed in the bond model development and application. 


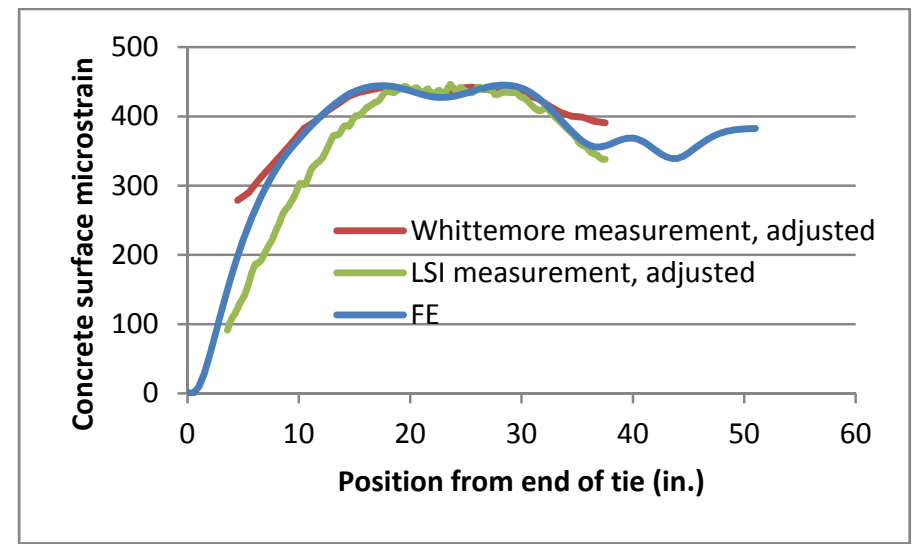

Figure 10: Adjusted Whittemore gauge and LSI measurements versus $\mathrm{FE}$ prediction of the surface strain profile of plant made concrete crossties $(1 \mathrm{in} .=25.4 \mathrm{~mm})$.

\section{Center Negative Moment Test on Concrete Crossties}

The American Railway Engineering and Maintenance-ofWay Association (AREMA) manual specifies a center negative moment test for monoblock concrete ties [16]. A diagram of the test is reproduced in Figure 11 for a 102 in. $(2.59 \mathrm{~m})$ tie. In this test, a concrete tie is placed upside down with its rail seats resting on two rubber supports, each being 30 in. (762 mm) away from the tie center. The tie bottom is then loaded by a force $P$ over a 6 in. $(152.4 \mathrm{~mm})$ length at the center until $P$ meets a specified pass/fail criterion.

Five concrete ties were retrieved at the derailment site of the July 18, 2013 accident in Bronx, New York, and one unused concrete tie manufactured in the same time period as the five used ties was also obtained. All six ties were tested under the AREMA test condition described above, but the test procedure was changed so that the ties were loaded to complete failure [17]. The evolution of the load and the rail seat displacement relative to the tie center was recorded in the test. Upon completion of the modified center negative moment test, two concrete samples were drilled from each tie, and standard material tests were conducted on the samples. Table 4 shows the average concrete material parameters obtained in the material tests on the samples from the unused tie.

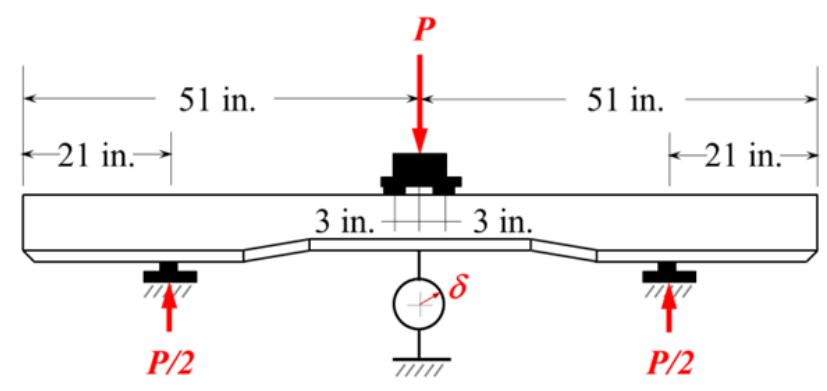

Figure 11: AREMA center negative moment test specification for monoblock concrete ties [16], reproduced for a $102 \mathrm{in.}(2.59 \mathrm{~m})$ tie $(1 \mathrm{in.}=\mathbf{2 5 . 4} \mathrm{mm})$.
Table 4. Average concrete material parameters for the unused concrete tie subjected to the modified AREMA center negative moment test.

\begin{tabular}{ccccc}
\hline \multirow{2}{*}{ Density } & $\begin{array}{c}\text { Elastic } \\
\text { modulus }\end{array}$ & $\begin{array}{c}\text { Poisson's } \\
\text { ratio }\end{array}$ & $\begin{array}{c}\text { Split tensile } \\
\text { strength }\end{array}$ & $\begin{array}{c}\text { Compressive } \\
\text { Strength }\end{array}$ \\
\hline $140.5 \mathrm{lb} / \mathrm{ft}^{3}$ & $4,941.0 \mathrm{ksi}$ & 0.202 & $1,012.5 \mathrm{psi}$ & $10,138.5 \mathrm{psi}$ \\
$\left(2,251 \mathrm{~kg} / \mathrm{m}^{3}\right)$ & $(34.1 \mathrm{GPa})$ & & $(6.98 \mathrm{MPa})$ & $(69.9 \mathrm{MPa})$ \\
\hline
\end{tabular}

FE simulations of the modified AREMA center negative moment test were conducted to evaluate the ultimate center negative moment capacity of the concrete ties involved in the July 18, 2013 accident in Bronx, New York. The frictional bond model was applied in the preliminary analyses [18], and this paper further employed the adhesive, frictional and dilatational bond model in the analyses of the unused tie. Parameters in Table 4 and Table 2 were employed for the concrete and bond models, respectively. The force-relative rail seat displacement relations obtained from the simulations are compared with the test data in Figure 12.

While the test data corresponds to one single test conducted on one unused concrete tie and thus does not display any experimental variability, the simulation results using either bond model appear to match fairly closely with the test data. The predicted failure loads (maximum load) by the frictional model and the adhesive/frictional/dilatational model are within $4.9 \%$ and $11.3 \%$, respectively, of the failure load observed in the test. The predicted relative rail seat displacements at failure tend to be lower than the corresponding test data, and it is postulated that this could be related to the concrete material characterization. A stronger bond is presented in the adhesive, frictional and dilatational model than in the frictional model. While the stronger bond does not appear to affect the elastic portion of the force-displacement response, it does result in a higher failure load.

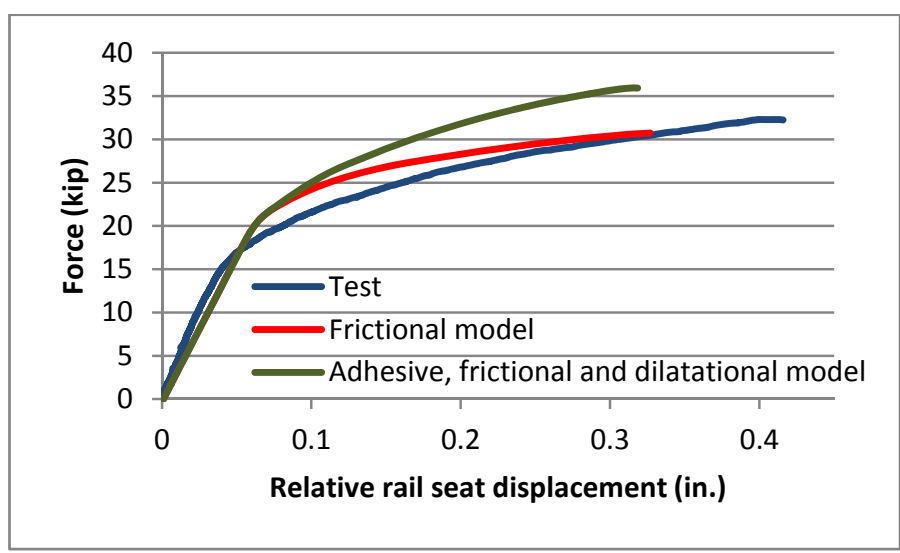

Figure 12: Force-relative rail seat displacement relations obtained from the modified AREMA center negative moment test versus FE simulations using two bond models $(1 \mathrm{kip}=4.448 \mathrm{kN}, 1$ in. $=25.4 \mathrm{~mm})$. 


\section{SUMMARY AND CONCLUSIONS}

Elasto-plastic bond models were developed for the interface between the seven-wire prestressing strands and concrete in the railroad concrete tie application. A frictional bond model and an adhesive, frictional and dilatational bond model are presented in this paper. The bond parameters for the adhesive, frictional and dilatational model were calibrated from laboratory strand pullout and pretensioned prism tests conducted on concrete specimens embedded with seven-wire strands. The bond models were then verified with two independent sets of test data: (1) the concrete surface strain profile measured on actual concrete ties made in a plant, and (2) the force-relative rail seat displacement relation obtained in a modified AREMA center negative moment test. With appropriate creep strain adjustments, the surface strain profile predicted by the FE method using the adhesive, frictional and dilatational bond model falls within the scattering of the experimental measurements. The force-relative rail seat displacement relations predicted by the FE method using both bond models agree reasonably well with the data from the modified AREMA center negative moment test. The stronger bond depicted by the adhesive, frictional and dilatational bond model does not appear to affect the elastic portion of the forcedisplacement relation, but it predicts an ultimate failure load $17 \%$ higher than the FE prediction using the friction only bond model.

\section{ACKNOWLEDGEMENT}

The work described in this paper was sponsored by the Office of Research, Development and Technology, Federal Railroad Administration, U.S. Department of Transportation. Directions provided by Messrs. Gary Carr and Cameron Stuart of the Track Research Division are gratefully acknowledged. The authors would like to thank Professors Robert J. Peterman and B. Terry Beck of Kansas State University for sharing the test data applied in this study.

\section{REFERENCES}

[1] Yu, H., Jeong, D., Marquis, B., and Coltman, M., 2015, "Railroad Concrete Tie Failure Modes and Research Needs," 2015 Transportation Research Board 94th Annual Meeting, TRB15-0311.

[2] Mayville, R. A., Jiang, L., and Sherman, M., 2014, "Performance Evaluation of Concrete Railroad Ties on the Northeast Corridor," Report No. DOT/FRA/RPD-14/03.

[3] National Transportation Safety Board, 2014, "Railroad Accident Brief - Metro-North Railroad Derailment," Report No. NTSB/RAB-14/11.

[4] National Transportation Safety Board, 2014, "Materials Laboratory Factual Report," Report No. 14-052.

[5] Dassault Systèmes, 2012, Abaqus Analysis User's Manual.

[6] Yu, H., Jeong, D. Y., Choros, J., and Sussmann, T., 2011, "Finite Element Modeling of Prestressed Concrete Crossties with Ballast and Subgrade Support." Proc.
ASME 2011 International Design Engineering Technical Conferences \& Computers and Information in Engineering Conference, DETC2011-47452.

[7] Yu, H., and Jeong, D. Y., 2012, "Railroad Tie Responses to Directly Applied Rail Seat Loading in Ballasted Tracks: A Computational Study," Proc. ASME/ASCE/IEEE 2012 Joint Rail Conference, JRC2012-74149.

[8] Zienkiewicz, O. C., and Taylor, R. L., 1991, The Finite Element Method. Vol. 2. Solid and Fluid Mechanics Dynamics and Non-Linearity, Fourth Edition, McGrawHill, London.

[9] Michalowski, R., and Mroz, Z., 1978, "Associated and Non-Associated Sliding Rules in Contact Friction Problems," Archives of Mech., 30(3), pp. 259-276.

[10] Yu, H., and Jeong, D. Y., 2014, "Bond between Smooth Prestressing Wires and Concrete: Finite Element Model and Transfer Length Analysis for Pretensioned Concrete Crossties," Proceedings of the 2014 ASCE Structures Congress, Boston, Massachusetts.

[11] Arnold, M. L., Peterman, R. J., Bodapati, N. N. B., Beck, B. T., and Wu, C. H. J., 2013, "Development of a Standard Bond Test for Indented Prestressing Wires," Proc. 2013 Joint Rail Conference, JRC2013-2461.

[12] Bodapati, N. N. B., Zhao, W., Peterman, R. J., Wu, C. H. J., Beck, B. T., Haynes, M., and Holste, J. R., 2013, "Influence of Indented Wire Geometry and Concrete Parameters on the Transfer Length in Pretensioned Concrete Crossties," Proc. 2013 Joint Rail Conference, JRC2013-2463.

[13] Baltay, P., and Gjelsvik, A., 1990, "Coefficient of Friction for Steel on Concrete at High Normal Stress," J. Mater. Civ. Eng., 2(1), pp. 46-49.

[14] Bazant, Z. P., and Baweja, S., 2000, "Creep and Shrinkage Prediction Model for Analysis and Design of Concrete Structures: Model B3," ACI Special Publications, 194, pp. 1-84.

[15] Bodapati, N. N. B., Peterman, R. J., Zhao, W., Beck, B. T., Wu, C. H. J., Holste, J. R., Arnold, M. L., Benteman, R., and Schweiger, R., 2013, "Transfer-Length Measurements on Concrete Railroad Ties Fabricated with 15 Different Prestressing Reinforcements," Proc. 2013 PCI Convention and National Bridge Conference.

[16] American Railway Engineering and Maintenance-of-Way Association, 2010, Manual for Railway Engineering, Chapter 30, Part 4: Concrete Ties.

[17] Wiss, Janney, Elstner Associates, 2014, "Concrete Tie Testing and Petrographic Services," Report No. NTSB-R140003.

[18] Marquis, B., LeBlanc, J., Yu, H., and Jeong D., 2014, "CSX Derailment on Metro-North Tracks in Bronx, NY, July 18, 2013," Report to National Transportation Safety Board,

http://dms.ntsb.gov/pubdms/search/document.cfm?docID $=417234 \&$ docketID $=55312 \&$ mkey $=87518$ 